๑̊ Entomologica Fennica. 19 June 1996

\title{
Comparison of invertebrate abundance and biomass between a clear-cut stand and four stands under tree cover in Swedish boreal coniferous forests
}

\author{
Ola Atlegrim \& Kjell Sjöberg
}

\begin{abstract}
Altegrim, O. \& Sjöberg, K.: Comparison of invertebrate abundance and biomass between a clear-cut stand and four stands under tree cover in Swedish boreal coniferous forests. - Entomol. Fennica 7:17-27.

This study assesses differences between a seven-year old clear-cut and four forest habitats as regards abundance and biomass of different invertebrate taxa — important for habitat quality for insectivorous birds. Forest types studied were pine bog, spruce mire, mesic spruce and pine heath forest. Data were collected in the second half of June 1984 (to coincide with the peak feeding demands of many nestling birds). Results indicate that the clear-cut differed more from the tree covered habitats with respect to the field layer fauna than with respect to the terricolous fauna. Compared to the forest habitats, the clear-cut was characterized by a higher abundance and biomass of sap-suckers (Hemiptera: Homoptera and Heteroptera) but a lower abundance and biomass of leaf-eating herbivorous larvae (Hymenoptera: Symphyta and Lepidoptera) in the field layer. The difference with respect to leaf-eating larvae was probably caused by low abundance of larvae food plants in the clear-cut. This may be an important ecological difference because these larvae can be an important food source for insectivorous birds.
\end{abstract}

Altegrim, O. \& Sjöberg, K., Dept. of Animal Ecology, Swedish University of Agricultural Sciences, S-901 83 Umeå, Sweden

Received 2 June 1994, accepted 1 June 1995

\section{Introduction}

Most of the boreal Fennoscandian forest is used by commercial forestry. Effects of different silvicultural practices on invertebrate fauna have been reviewed by Heliövaara \& Väisänen (1984). They concluded that direct effects on the species composition and diversity of forest invertebrates are usually striking but transient. In northern Sweden the clear-cutting system is the system most commonly used. The entire tree-layer is removed, and thereafter the clear cut is prepared for seeding or planting. However, in pine (Pinus sylvestris) stands, seed trees are often left for natural regeneration of the forest. The re- moval of the tree-layer increases the amount of solar radiation on the soil surface which results in more extreme temperature conditions and changes in moisture conditions (Heliövaara \& Väisänen 1984).

Previous studies of the effects of clear-cutting on invertebrates have focused mainly on effects on tree- and soil-living invertebrates. For both these faunas, specialists are replaced by generalist species (Szujecki 1979). However, Huhta et al. (1967) concluded that changes in soil faunas were not conspicuous as the same species continue to dominate, but the number of species increases due to immigration of new species. For terricolous taxa, 
Huhta et al. (1967) found a sudden increase of diptera larvae and adult Coleoptera, a slow increase of Collembola, an initial increase followed by a decrease of Acarina and Coleoptera larvae, and a decrease in Araneae. Coyle (1981) showed that there were changes in functional groups of spiders after clear-cutting, i.e. a decrease in web-building spiders and an increased diversity of ground living hunters who use vision to detect and capture prey (hereafter called visually-hunting spiders). Huhta (1971) found that the spider fauna recovered to approximately the same density within $7-8$ years after clear-cutting after an initial decrease. The macroinvertebrate fauna of clear-cuts and mature forests was compared by Helle and Muona (1985), who found a higher total abundance and higher abundance of Homoptera, Diptera, Hymenoptera:Formicidae, Coleoptera and Gastropoda within the forests.

Effects on the field layer fauna have not been studied as intensively as the soil and terricolous fauna. According to Heliövaara \& Väisänen (1984) the field layer fauna is heavily affected due to elimination of shrubs, e.g. bilberry (Vaccinium myrtillus), and replacement by open field and meadow plant species. Thus, invertebrates associated with shrubs may disappear in clear-cuts. Immigration of herbs to clearcut areas can result in an increase of insects associated with herbs (Svensson 1986), replacing the shrub fauna. After clear-cutting the stand will gradually tum into a grass-dominated community. The practise of soil scarification, to prepare a site for tree planting, may prolong the turnover transition into grassland, and large areas may be without a field layer for a long time. In such situations effects on the field layer may be even more severe.

In the present study we focused on the terricolous (i.e. living on the ground and to some extent within the soil) and field layer invertebrate fauna. Our approach was to compare a seven-year-old clearcut stand with four forest stands, each representing a different boreal coniferous forest type, to determine what these habitats could offer insectivorous birds with respect to the abundance and biomass of the invertebrates. We therefore collected data on invertebrates during the second half of June when many forest birds raise their nestlings and food demands are high.

\section{Study area}

The study area (ca. 20 ha), is located in the Middle Boreal Zone (Ahti et al. 1968), $5 \mathrm{~km} \mathrm{~N}$ of Umeå, Sweden (long. $63^{\circ} 55^{\prime} \mathrm{N}$, lat. 20 $22^{\prime} \mathrm{E}$ ). It is characterized by a mosaic of dominant heathforest stands of pine (Pinus sylvestris L.) and spruce (Picea abies L.) intermingled with small open mires edged by narrow, wet, mire forests.

The following habitats were studied:

1) Pine bog forest: a sunlit "true dwarf-shrub pine bog" (Eurola et al. 1984) at the edge of a mire,

2) Spruce mire forest: a shady "spruce mire of Vaccinium myrtillus type", locally on sites more influenced by ground water, of "Rubus chamaemorus" type (Eurola et al. 1984),

3) Mesic spruce forest: a shady, mesic spruce heath forest of Vaccinium - Myrtillus type (Kalela 1961), with a field layer dominated by Vaccinium myrtillus and with $V$. vitis-idea as codominant,

4) Pine heath forest: a sunlit, dry pine heath forest of Empetrum - Myrtillus type (Kalela 1961) in which the field layer is dominated by Empetrum hermaphroditum, V. vitis-idea and V. myrtillus, and

5) Clear-cut: a stand clear-cut seven years ago, in which a sparse bushlayer consisting of birch (Betula sp.) had developed. Field layer vegetation was poorly developed and dominated by Deschampsia sp.

These forest habitats are characterized by a variety of light and moisture regimes. Tree cover is about $30 \%$ in the pine bog and pine heath forest, about $60 \%$ in the spruce mire and $70 \%$ in the spruce forest. The pine heath forest is the driest habitat followed by the mesic spruce forest, the spruce mire and pine bog forest.

\section{Methods}

Five sampling locations were randomly located within each of the five habitats. Five pitfall traps were placed in a randomized order at each sampling location. Plastic jars, $7 \mathrm{~cm}$ high and $7 \mathrm{~cm}$ in diameter, were used as pitfall traps. They were half-filled with a 1:1 mixture of ethylene glycol and 


\section{Terricolous}
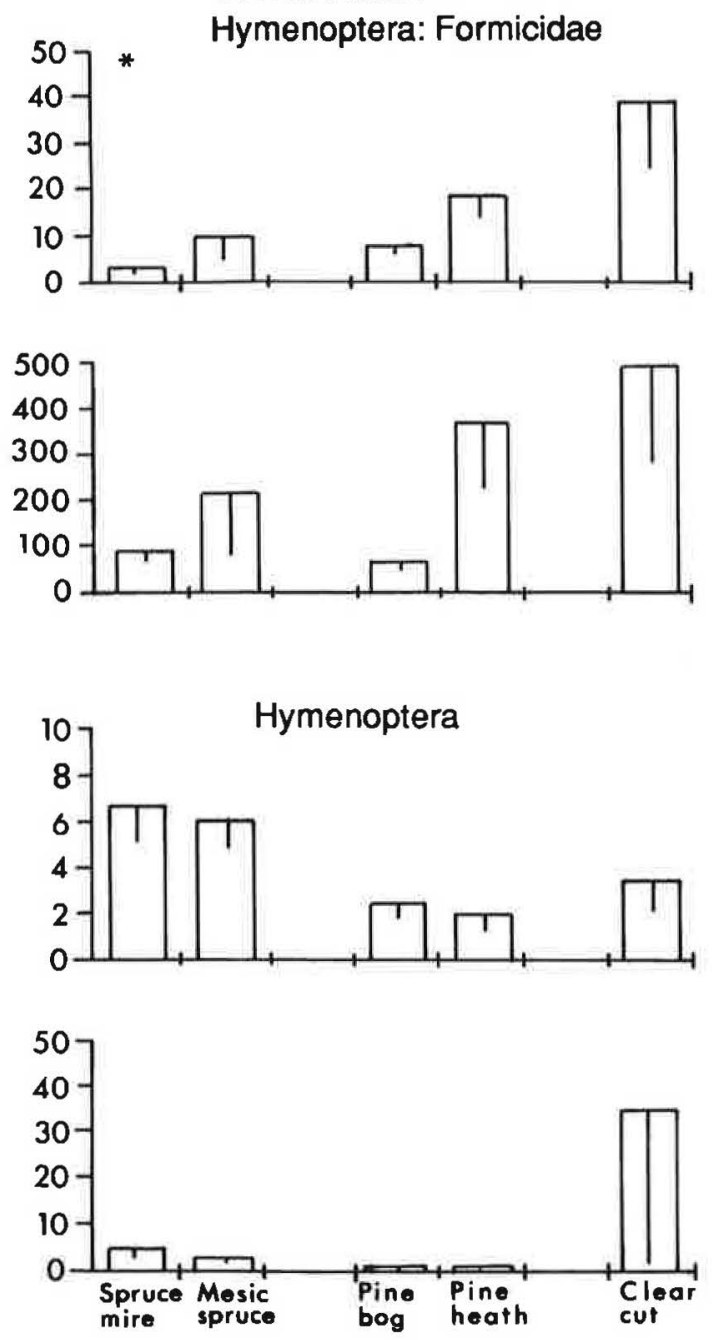

Field layer

Hymenoptera: Formicidae
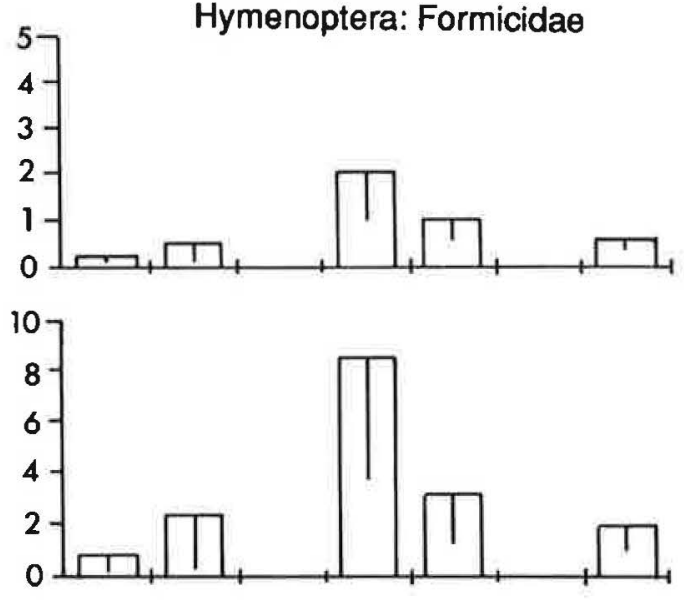

Hymenoptera
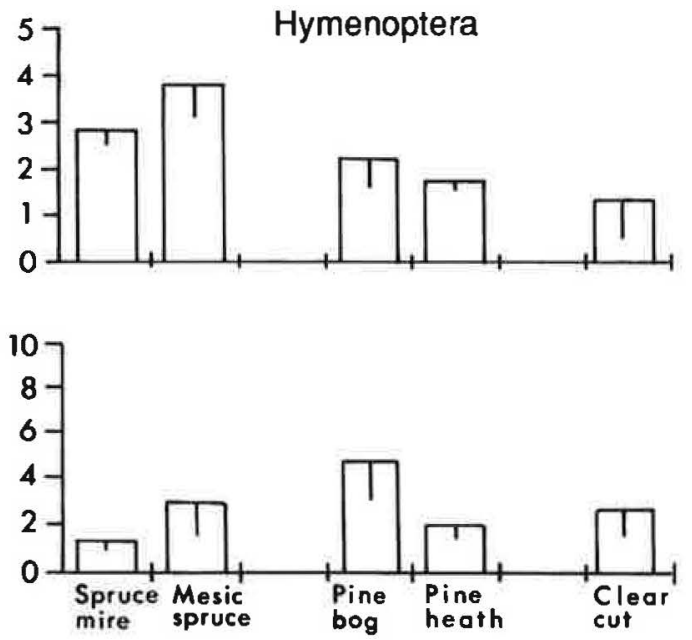

Fig. 1. Abundance (upper figure) and biomass (lower figure) of terricolous (left) and field layer (right) ants (Hymenoptera: Formicidae) and adult hymenopterans (excluding ants, Hymenoptera) within the five studied habitats. Each bar represents a mean value of five randomly located stations. The value for each station was a mean value of five pitfall traps for terricolous invertebrates and three sweepnet samples for field layer invertebrates. The line within each bar represents $\pm S$. E. A star above the bar of a forest habitat indicates a significant difference between the forest habitat and the clear-cut, modified Dunnetts test (Zar 1984), $\alpha=0.05$.

water with a surface-tension reducer added. Traps were put out June 12 and were collected and taken to the laboratory June 28. Each trap was sorted and invertebrates preserved in $70 \%$ alcohol. All insects were identified to order and, in some cases to family level, and/or divided into adults (imago) and young (larva). All invertebrates were counted and then weighed to the nearest 0.001 gram. Three sweep-net (diameter $0.25 \mathrm{~m}$ ) samples were taken on June 21 at each sampling location. Each sample consisted of twenty sweeps in the field layer. Invertebrates caught in the sweep-net were preserved and identified the same way as the pitfall trap material. 


\section{Statistical treatment}

For each sampling location mean values were calculated for the abundance and biomass of each taxonimic group and pooled total values were calculated. In addition, a total sum, with ants excluded, was calculated for the pitfall traps. We compared the clear-cut stand with the four forest habitats by means of a modified Dunnett's test (Zar 1984) using rank sums for each habitat. This multiple test is preferred when one treatment (here, our control, the clear-cut) is compared to several other treatments (Zar 1984).

\section{Results}

\subsection{Terricolous invertebrates}

Mean numbers and biomasses of different taxa in the five studied habitats are shown in Figs. 1-7. Abundance of ants was higher in the clear-cut than in the spruce mire forests, but no differences were found for other hymenopterans (Fig. 1). Abundance and biomass of springtails did not differ between the clear-cut and the forest habitats (Fig. 2). Abundance and biomass of mites were significantly higher in the clear-cut compared to the two wet, shaded forest habitats (the spruce mire and mesic spruce forest; Fig. 2). However, no differences were found with respect to abundance and biomass of spiders (Fig. 2). Both abundance and biomass of homopterans were higher in the clear-cut than the spruce mire, mesic spruce and pine bog forest (Fig. 3). A higher abundance of flies was found in the clear-cut than the pine bog forest (Fig. 3), while biomass of flies was higher in the clear-cut than the pine heath forest (Fig. 3). Abundance of beetles did not differ between the clear-cut and the forest habitats but all forest habitats had a lower beetle biomass than the clear-cut (Fig. 4). However, both abundance and biomass of beetle larvae were lower in the clear-cut than in the pine bog forest (Fig. 4). The clear-cut had significantly fewer snails than the mesic spruce and pine heath forests, and a lower biomass of snails than in the spruce mire, mesic spruce and pine heath forests (Fig. 5). When ants were included, the clear-cut had a significantly higher total abundance than the spruce mire forest (Fig. 7). However, when ants were excluded there were no differences. Further, no differences were found with respect to the total biomass of invertebrates (Fig. 7).

\subsection{The field layer invertebrates}

No differences were found between the clear-cut and the forest habitats with respect to adult hymenopterans (Fig. 1). However, both the abundance and biomass of hymenoptera larvae were significantly lower in the clear-cut than in mesic spruce, pine bog and pine heath forests (Fig. 6). Abundance and biomass of springtails was higher in the spruce mire and the mesic spruce forests than in the clear-cut (Fig. 2). The pattern for homopterans is similar to that of the terricolous fauna, i.e. a higher abundance and biomass in the clear-cut compared to the spruce mire, mesic spruce and pine heath forest (Fig. 3). For heteropterans, the clearcut had a higher abundance and biomass than the spruce mire, pine bog and pine heath forests (Fig. 6). The abundance of flies was significantly lower in the pine heath forest than in the clear-cut, but no differences were found with respect to the biomass of flies (Fig. 3). However, the abundance of midges was significantly lower in the clear-cut than in the spruce mire, mesic spruce and pine heath forests (Fig. 6). There were no differences with respect to beetles and beetle larvae (Fig. 4). Both abundance and biomass of lepidoptera larvae were significantly higher in the two wet, shaded forests, i.e. the spruce mire and the mesic spruce forest, compared to the clear-cut (Fig. 6). The clear-cut did not differ from the forest habitats in the abundance or biomass of mites (Fig. 2). Abundance of spiders was significantly higher in the spruce mire, mesic spruce and pine bog forest while biomass of spiders was significatly higher in the pine bog forests than in the clear-cut (Fig. 2). Total abundance of invertebrates did not differ between clear-cut and forest habitats (Fig. 7). However, the total biomass of invertebrates was significantly lower in the clearcut than in the spruce mire and the mesic spruce forests (Fig. 7).

\section{Discussion}

The clear-cut area studied was seven years old, and therefore effects of tree removal on the invertebrate 


\section{Terricolous}
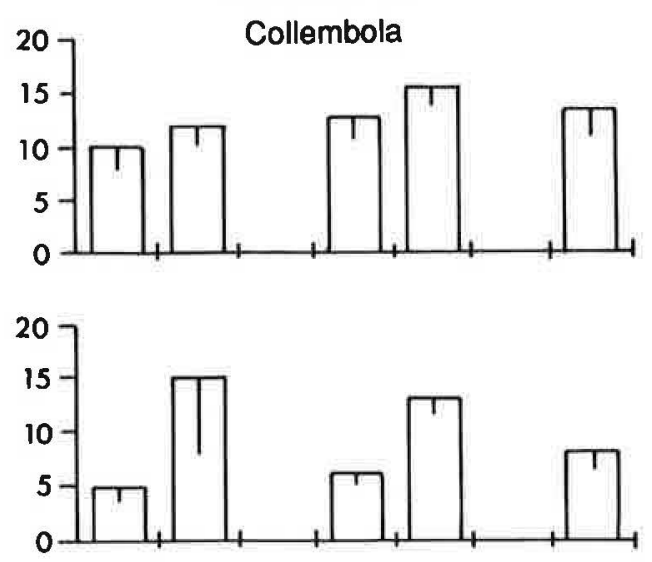

Acari
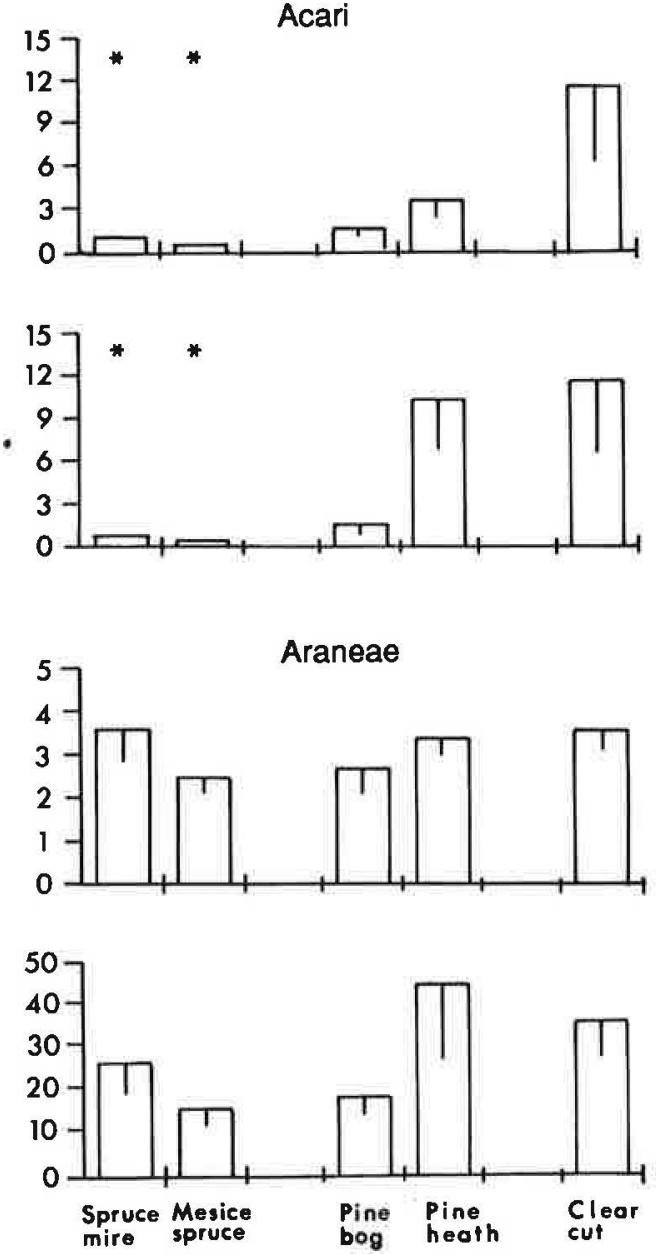

Field layer
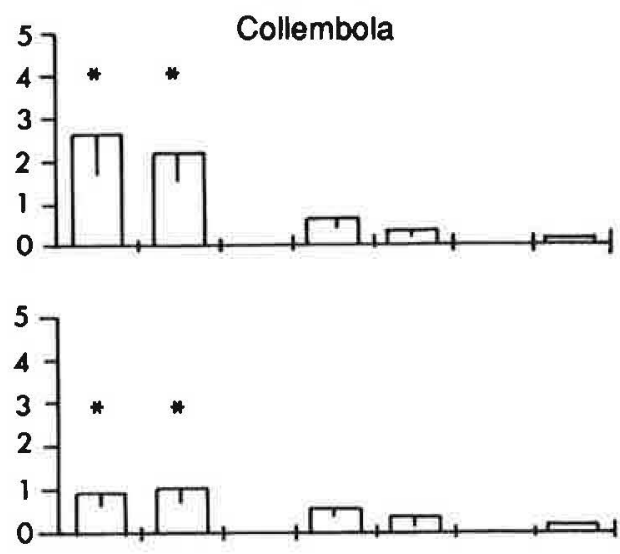

Acari
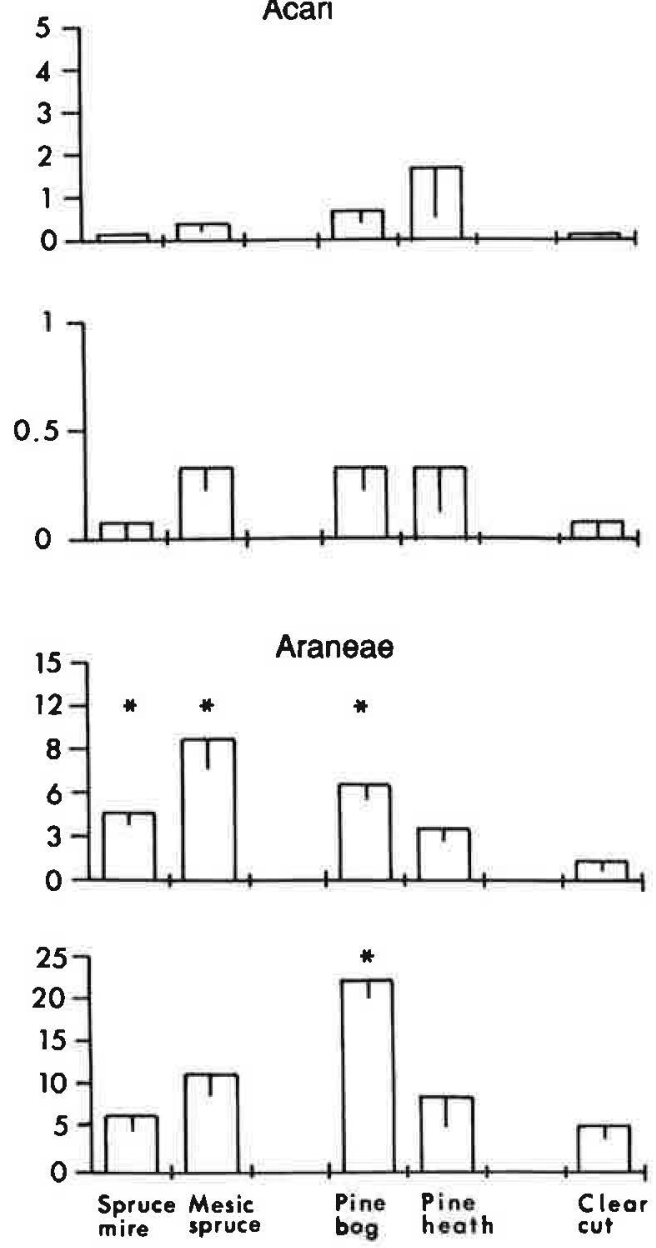

Fig. 2. Abundance (upper) and biomass (lower) of terricolous (left) and field layer (right) springtails (Collembola), mites (Acari) and spiders (Araneae) within the five studied habitats. Otherwise as in Fig. 1. 

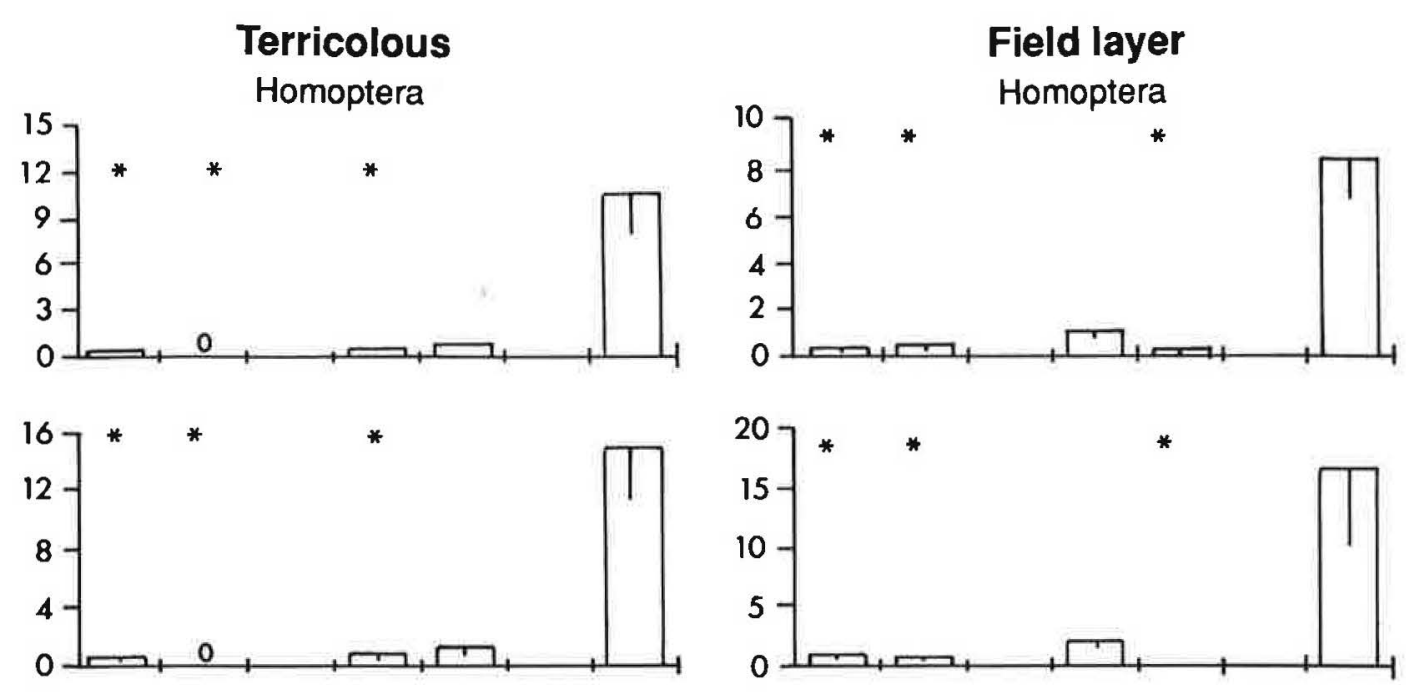

\section{Diptera}
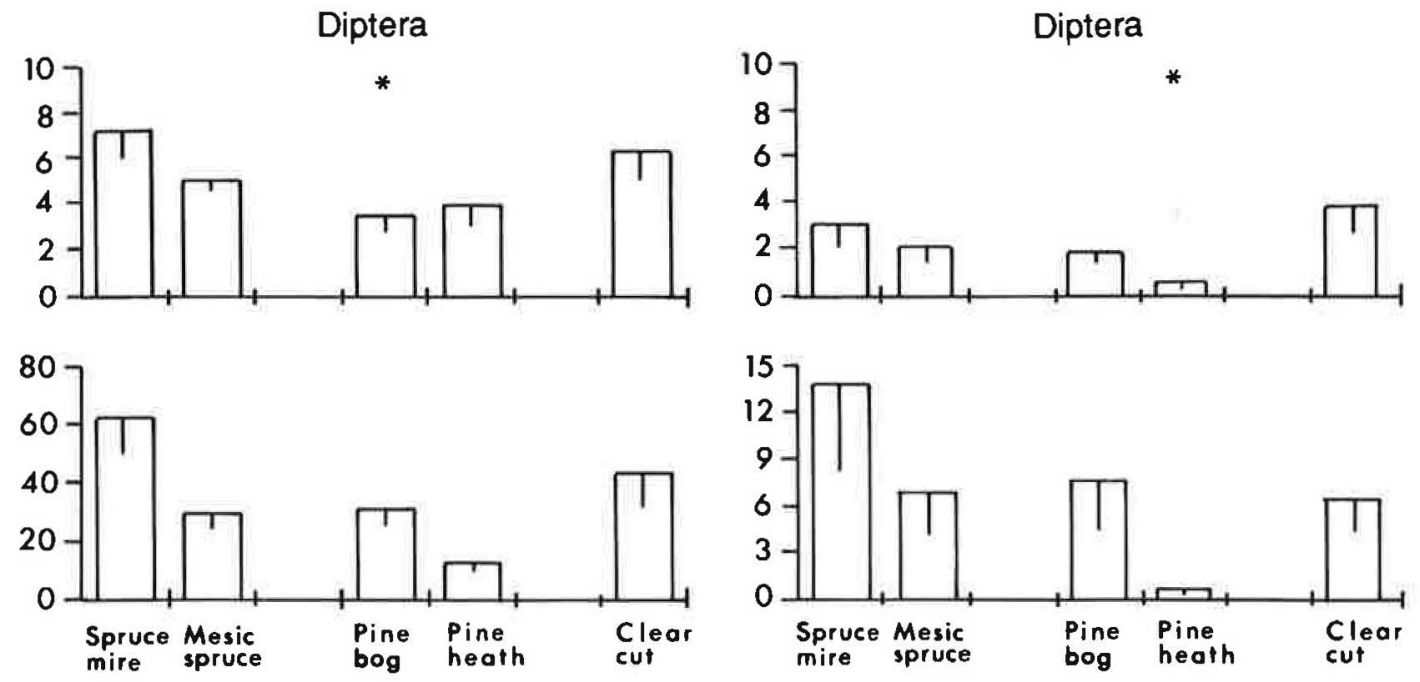

Fig. 3. Abundance (upper) and biomass (lower) of terricolous (left) and field layer (right) homopterans (Hemiptera: Homoptera) and flies (Diptera) within the five studied habitats. For the field layer flies, midges (Diptera: Nematocera) are excluded, see Fig. 6. Otherwise as in Fig. 1.

fauna may have somewhat faded, in agreement with the review by Heliövaara \& Väisänen (1984). For example Huhta (1976) found that terricolous beetles after an initial increase had reached approximately the original abundance nine years after cutting. In the present study, the clear-cut and the pine heath forest (the forest type which most resembled the clear-cut stand before cutting) differed with respect to the terricolous fauna only in the biomass and abundance of snails, and biomass of flies (Figs. 3 and 5). This may indicate that the effects of tree layer removal had faded with respect to the terricolous fauna. However, with respect to the field layer fauna, differences between the clearcut and the pine heath forest were found for flies, homopterans, heteropterans, midges and sawfly larvae (Figs. 3 and 6). The greater number of differences indicates that the field layer fauna in the 

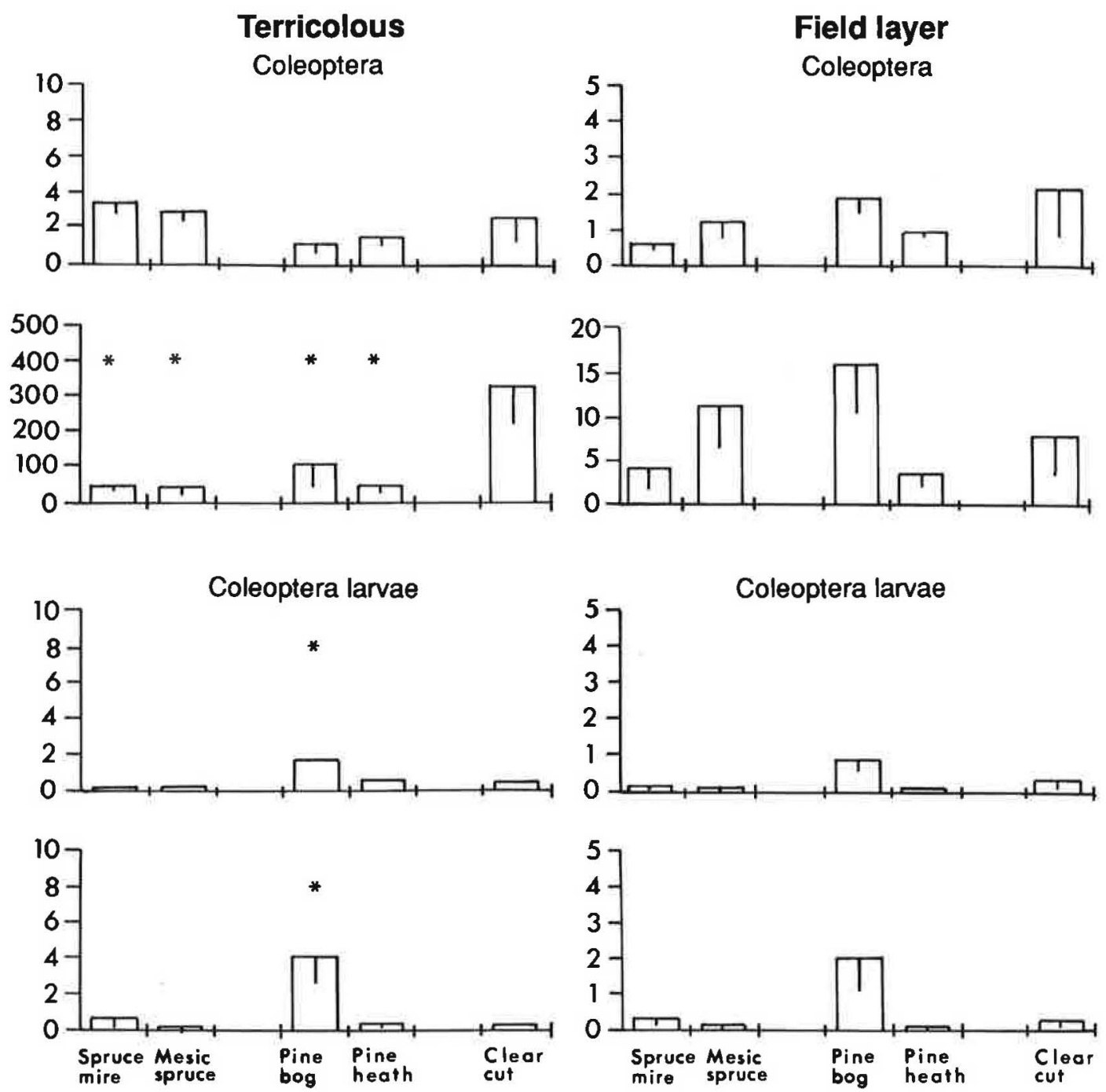

Fig. 4. Abundance (upper) and biomass (lower) of terricolous (left) and field layer (right) beetles and beetle larvae (Coleoptera) within the five studied habitats. Otherwise as in Fig. 1.

clear-cut differs to a higher extent from the pine heath forest and that the effects of tree removal seems to be more severe and prolonged compared to effects on the terricolous fauna.

The clear-cut stand differed less frequently from the forest habitats with respect to the terricolous fauna (a total of 25 differences) than with respect to the field layer fauna (a total of 34 differences). These results agree with Helövaara \& Väisänen
(1984), where the most severe effects are expected to be incurred by the field layer fauna. In general, for differences found with respect to the terricolous fauna (with the exception of snails), the clear-cut had higher invertebrate abundance and biomass than the forest habitats. For the field layer fauna the results were more mixed.

The only significant difference found with respect to total abundance of terricolous invertebrates 

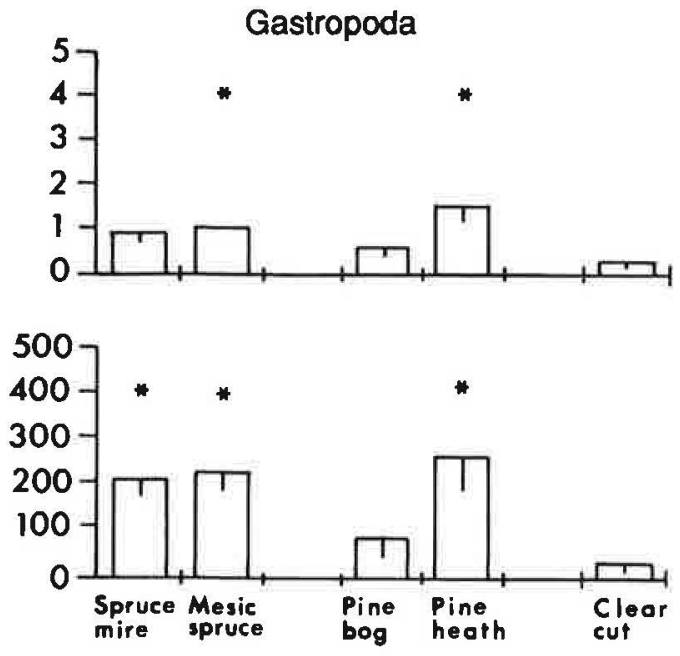

Fig. 5. Abundance (upper) and biomass (lower) of terricolous snails (Gastropoda) within the five studied habitats. Otherwise as in Fig. 1.

was a higher total abundance in the clear-cut than in the spruce mire forest (Fig. 7). Previous studies have also shown that the terricolous fauna recovers after clear-cutting but that recovery times vary (Huhta 1971, 1976, Helle \& Muona 1985). For the total biomass of field layer invertebrates, we found significantly lower biomass in the clear-cut than in the spruce mire or the mesic spruce forest (Fig. 7). Kastdalen \& Wegge (1985) found that the density of field layer invertebrates after tree planting reached the same level as before cutting in mixed coniferous forests but not in rich bog forests. Although the frequency of differences found between the clearcut and the forest habitats were few with respect to total abundance and biomass, there were conspicuous differences at lower taxonomic levels.

At these lower taxonomic levels differences in temperature and moisture conditions between clear-cut and forest habitats could be important for invertebrate fauna. For example, Huhta et al. (1967) considered moisture conditions the most important factor for the soil fauna. The succession of the clear-cut, e.g. immigration of new field layer plants and growth of a planted tree layer, will eventually reduce the effects of tree layer removal and result in more constant conditions. However, the clear-cut area studied here was only seven years old and the planted trees
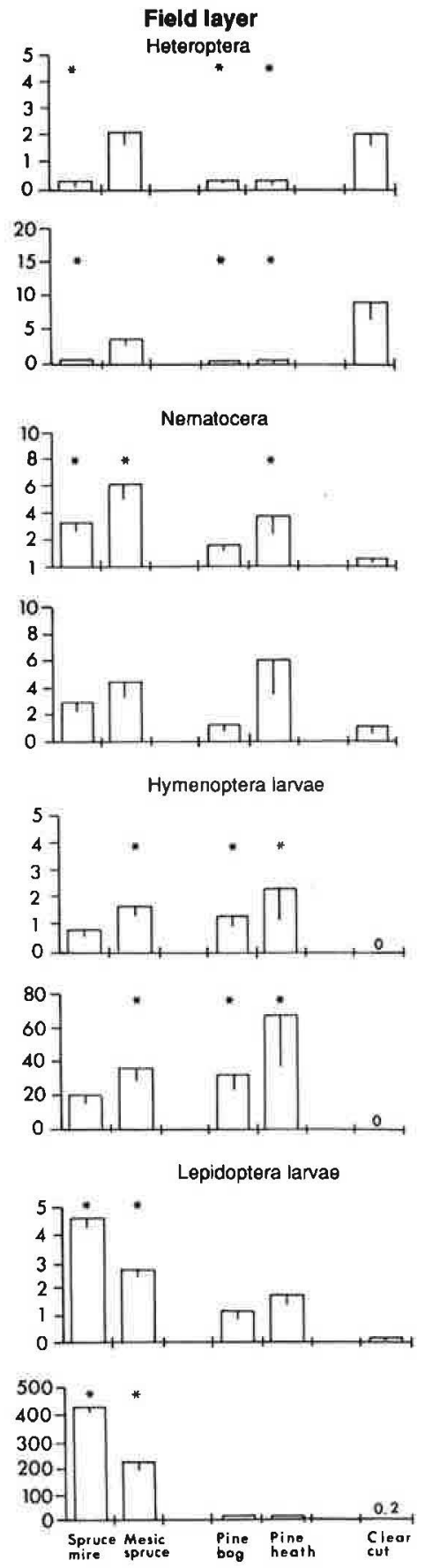

Fig. 6. Abundance (upper) and biomass (lower) of field layer heteropterans (Hemiptera: Heteroptera) and midges (Diptera: Nematocera), sawtly larvae (Hymenoptera: Symphyta) and lepidoptera larvae (Lepidoptera) within the five studied habitats. Otherwise as in Fig. 1. 


\section{Terricolous}
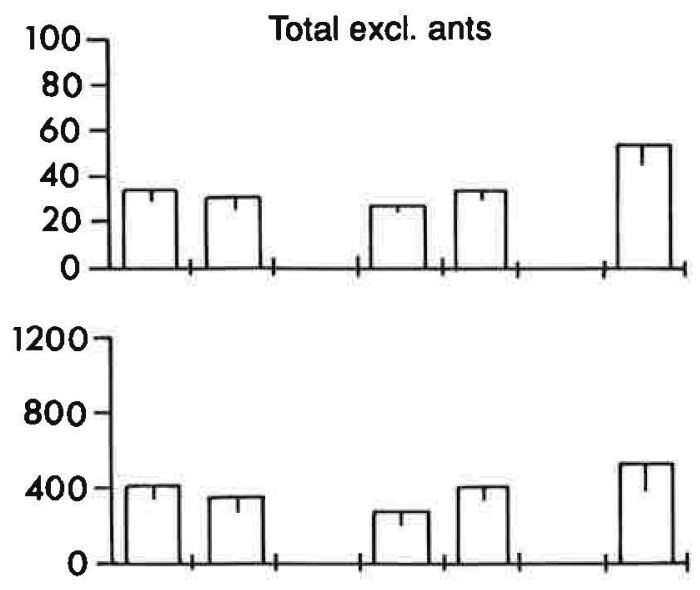

\section{Field layer}
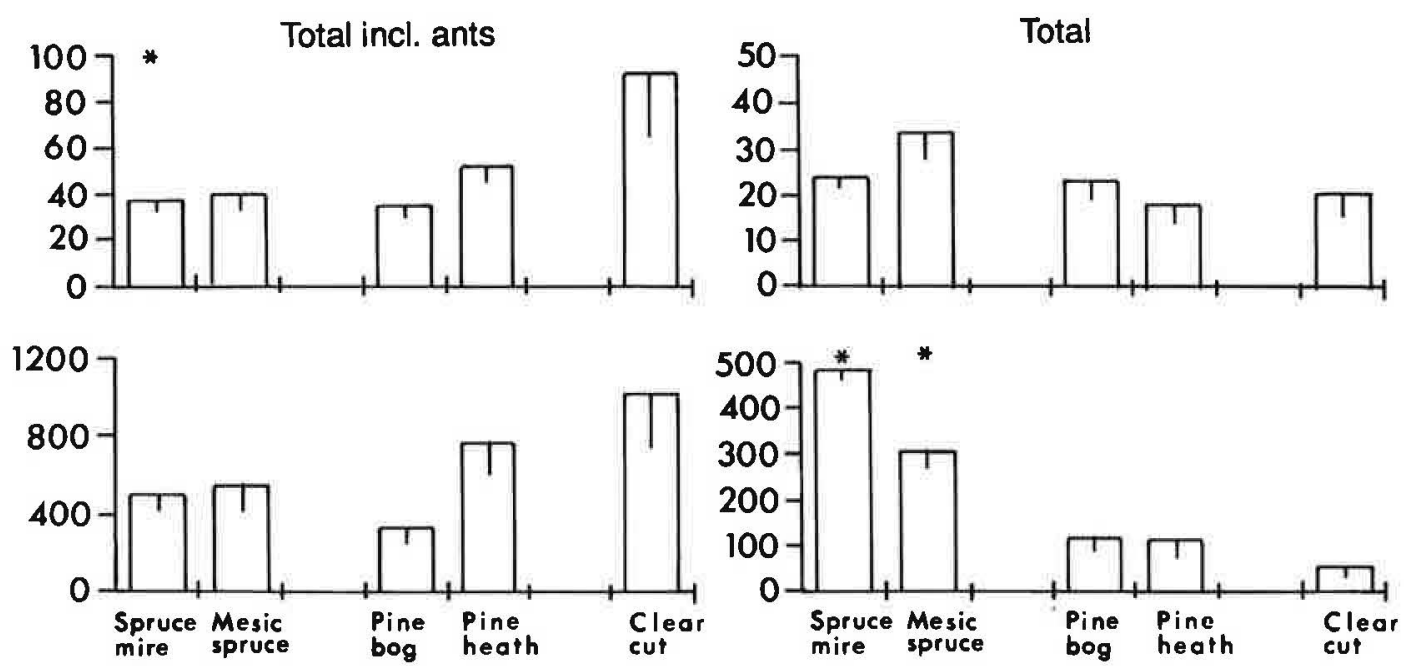

Fig. 7. Total abundance (upper) and biomass (lower) of terricolous (left) and field layer (right) invertebrates within the five studied habitats. For terricolous invertebrates a total with ants (Hymenoptera: Formicidae) excluded is shown in the two figures at the upper left. Otherwise as in Fig. 1.

were very small. Further, the field layer, which to a great extent consisted of grass (Deschampsia), was poorly developed with large areas of bare ground.

A likely explanation for the differences found with respect to snails may be that the dry conditions in the clear-cut resulted in lower snail abundance and biomass (Fig. 5). This is in agreement with Helle and Muona (1985). The higher biomass of beetles in the clear-cut may be explained by the presence of the large Hylobius abietis, contributing significantly to the high biomass.

Coyle (1981) and McIver et al. (1992) showed that the composition of spider fauna changed due to clear-cutting. A dominance of web-building spiders in the forest habitats changed to a dominance of visually-hunting spiders after clear-cutting. We did not find any significant differences with respect to terricolous spiders (Fig. 2). This agrees with Huhta (1971) who found similar abundances of 
terricolous spiders in clear-cuts and in forest habitats 7-8 years after cutting. For field layer spiders we found, however, significantly lower abundance in the clear-cut compared to the spruce mire, mesic spruce and pine bog forest, respectively (Fig. 2). Since these spiders mainly consisted of web-builders we interprete these results as an effect of the poorly developed field layer in the clear-cut (cf. Coyle 1981, McIver et al. 1992).

We can suggest no explanation for the higher abundance and biomass of field layer springtails in the two wet, shaded habitats compared to the clearcut (Fig. 2), but there was a similar significant decrease along a gradient from wet, shaded to dry, sunny forest (Atlegrim \& Sjöberg, unpubl. data). The abundance of midges in the field layer was also significantly higher in three of the four forest habitats than in the clear-cut (Fig. 6). The dry clear-cut habitat may be unsuitable for midges, but it is also possible that availability of flowers for nectar searching midges was higher in the forest habitats.

For the herbivorous taxa homopterans, heteropterans, sawfly and lepidoptera larvae we found several interesting patterns. Abundance and biomass of sap-suckers, i.e. homopterans and heteropterans, were higher in the clear-cut (Fig. 3 and 6), while the opposite pattern was found for leaf-eaters, i.e. sawfly and lepidoptera larvae, (Fig. 6). One reason for these patterns may be differences in food quality caused by tree-removal. Studies on psyllids (Homoptera: Psyllidae) have shown that a high concentration of soluble nitrogenous compounds is favourable (White 1970 and references therein). High concentrations of soluble nitrogen may be produced by plants receiving high solar radiation and/or being under water stress (White 1984). These conditions seem likely for the field layer plants in the clear-cut area and may explain the higher abundance and biomass of field layer homopterans and heteropterans in the clear-cut (Fig. 3 and 6). However, this pattern may also be caused by immigration of new plant species to the clear-cut. This was the explanation offered by Svensson (1986) for high abundance of the geometrid moth Spargania luctuata on clear-cuts. Both sawfly and lepidoptera larvae (Fig. 6), which showed the opposite pattern compared to the sap-suckers, was dominated by species feeding on leaves of the shrub field layer, especially the bilberry Vaccinium myrtillus and lingonberry Vaccinium vitis-idaea, within the for- ests. A reasonable explanation for their low abundance and biomass in the clear-cut is the shift in the dominance relationships within the field layer in the clear-cut, resulting in low occurance of shrubs. Also Kastdalen \& Wegge (1985) found an $80 \%$ reduction of larvae due to tree layer removal. The significant difference found between the clear-cut and the two wet, shaded forests with respect to total biomass of field layer invertebrates was probably due to the fact that lepidoptera larvae accounted for a high proportion of total biomass in the field layer in this study, and these larvae had high abundance in the spruce mire and mesic spruce forest (compare Fig. 6 and 7).

Results here show that even if the most severe effects of tree removal in the seven-year-old clearcut may have somewhat faded, differences still exist between the clear-cut and forest habitats. Differences may be even greater at lower taxonomic levels than those used in our study. With respect to invertebrate prey, the suitability of the clear-cut as a habitat compared to the forest habitats may therefore differ considerably for insectivorous birds. The low abundance and biomass of lepidoptera larvae within the field layer in the clear-cut may be of particular importance since this invertebrate group has been reported to be of great importance for these birds (e.g. Kastdalen \& Wegge 1985, Holmes \& Schultz 1988, Atlegrim \& Sjöberg 1995).

Acknowledgements. We would like to express our gratitute to John P. Ball for comments on the manuscript. The study was financed by the Swedish Environmental Protection Agency (SNV).

\section{References}

Ahti, T., Hämet-Ahti, L. \& Jalas, J. 1968: Vegetation zones and their sections in northwestern Europe. Ann. Bot. Fennici 5:169-211.

Atlegrim, O. \& Sjöberg, K. 1995. Effects of clear-cutting and selective felling in Swedish Boreal coniferous forest: response of invertebrate taxa eaten by birds. Entomol. Fennica 6:79-90

Coyle, F. A. 1981: Effects of clear-cutting on the spider community of a southern Appalachian forest. - J. Arachnol 9:285-298.

Eurola, S., Hicks, S. \& Kaakinen, E. 1984. Key to Finnish mire types. - In Moore, P. D. (ed.): European Mires. Academic Press, London, pp. 11-17.

Heliövaara, K. \& Väisänen, R. 1984: Effects of modern forestry on northwestern European forest invertebrates: 
a synthesis. - Acta For. Fenn. 189:1-32.

Helle, P. \& Muona, J. 1985: Invertebrate numbers in edges between clear-fellings and mature forests in northern Finland. — Silva Fennica 19:281-294.

Holmes, R. T. \& Schultz, J. C. 1988: Food availability for forest birds: effects of prey distribution and abundance on bird foraging. — Can. J. Zool. 66:720-728.

Huhta, V. 1971: Succession in the spider communities of the forest floor after clear-cutting and prescribed burning. - Ann. Zool. Fenn. 8:483-542.

- 1976: Effect of clear-cutting on numbers, biomass and community respiration of soil invertebrates. - Ann. Zool. Fenn. 13:63-80.

Huhta, V., Karppinen, E., Nurminen, M. \& Valpas, A. 1967: Effect of silvicultural practices upon arthropod, annelid and nematode populations in coniferous forest soil. - Ann. Zool. Fenn. 4:87-145.

Kalela, A. 1961: Waldvegetationszonen Finlands und ihre Klimatische Parallelltypen. - Arch. Soc. Zool. Bot. Fenn. 'Vanamo' 16:65-83.

Kastdalen, L. \& Wegge, P. 1985: Animal food in capercaillie and black grouse chicks in south east Norway-a preliminary report. — In: Hudson, P. J. \& Lovel,
T. W. I. (eds.): Proceedings of the 3rd International Grouse Symposium, York, England, 1984. World Pheasant Association, Reading, and Intemational Council for Game and Wildlife Conservation, Paris, pp. 499-509.

McIver, J. D., Parsons, G. L. \& Moldenke, A. R. 1992: Litter spider succession after clear-cutting in a western coniferous forest. — Can. J. For. Res. 22:984-992.

Svensson, I. 1986: Skovdrifts indflydelse på sommerfuglepopulationer. - Lepidoptera Bd V, 2:41-51. (In Danish.)

Szujecki, A. 1979: Some problems of zoocoenosis restoration in degraded forest habitats. - Memorabilia Zool. $32: 57-67$.

White, T. C. R. 1970: Some aspects of the life history, host selection, dispersal, and oviposition of adult Cardiaspina densitexta (Homoptera: Psyllidae), — Aust. J. Zool. 18:105-117.

- 1984: The abundance of invertebrate herbivores in relation to the availability of nitrogen. - Oecologia 63:90105.

Zar, J. H. 1984: Biostatistical Analysis. - Prentice-Hall, Inc., Englewood Cliffs, New Jersey, 718 pp. 